Provided for non-commercial research and education use. Not for reproduction, distribution or commercial use.

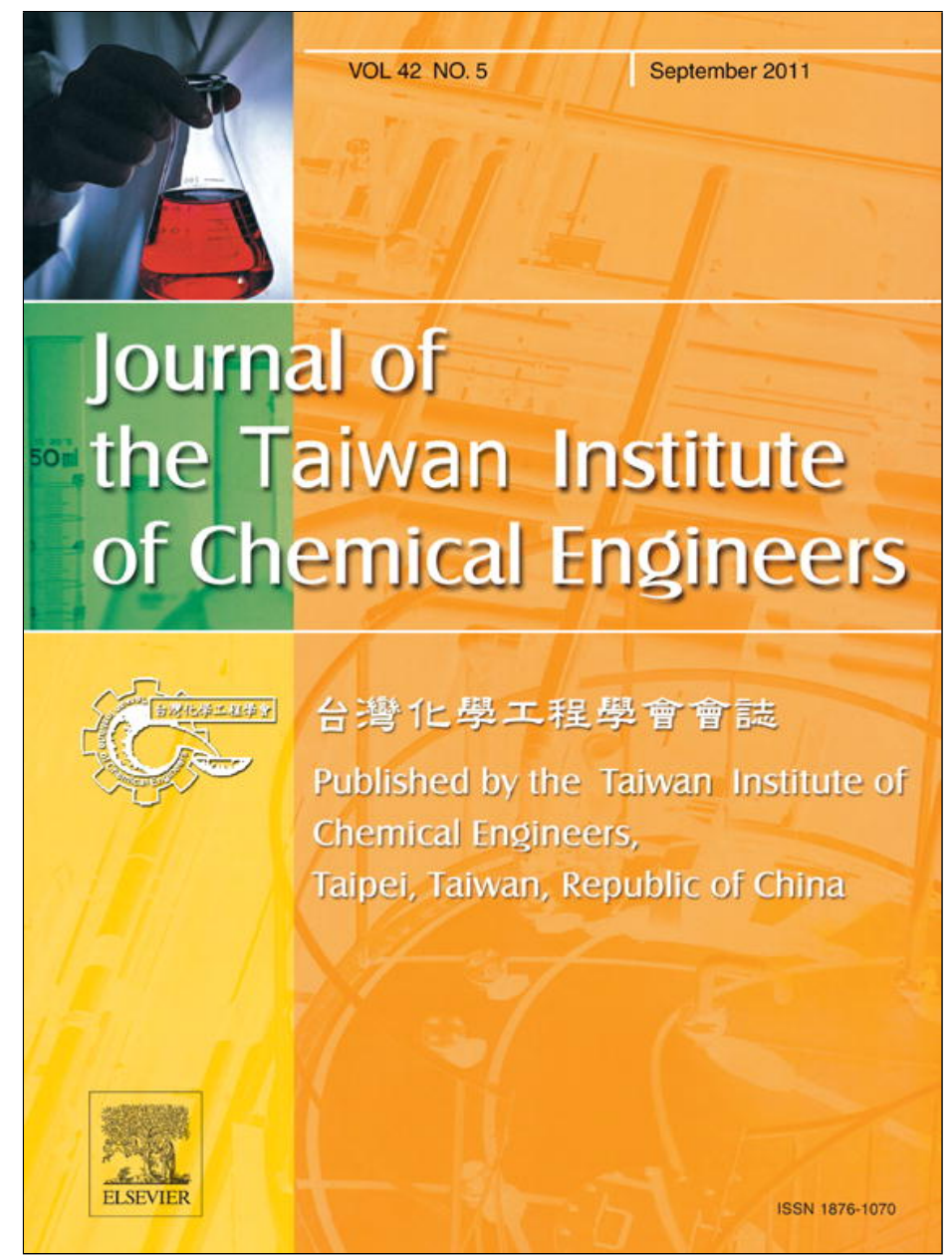

This article appeared in a journal published by Elsevier. The attached copy is furnished to the author for internal non-commercial research and education use, including for instruction at the authors institution and sharing with colleagues.

Other uses, including reproduction and distribution, or selling or licensing copies, or posting to personal, institutional or third party websites are prohibited.

In most cases authors are permitted to post their version of the article (e.g. in Word or Tex form) to their personal website or institutional repository. Authors requiring further information regarding Elsevier's archiving and manuscript policies are encouraged to visit:

http://www.elsevier.com/copyright 


\title{
Potential utilization of Jatropha curcas $L$. press-cake residue as new precursor for activated carbon preparation: Application in methylene blue removal from aqueous solution
}

\author{
Alfin Kurniawan, Suryadi Ismadji * \\ Department of Chemical Engineering, Widya Mandala Surabaya Catholic University, Kalijudan 37, Surabaya 60114, Indonesia
}

A R T I C L E I N F O

\section{Article history:}

Received 13 October 2010

Received in revised form 23 February 2011

Accepted 14 March 2011

Available online 8 May 2011

\section{Keywords:}

Active carbon

Adsorption

Mechanism

Methylene blue

Residue

\begin{abstract}
A B S T R A C T
Low cost activated carbon was prepared from the press-cake residue of Jatropha curcas L. The effectiveness of this activated carbon and its modified forms (chemical and thermal activation) was evaluated for methylene blue (MB) dye removal from aqueous solution. Adsorption experiments were conducted in batch system at various $\mathrm{pH}$ and temperatures. The widely used isotherm models, Langmuir and Freundlich, were employed to represent equilibrium data. Kinetic data were analyzed using pseudofirst order and pseudo-second order model. Thermodynamic properties $\left(\Delta G^{0}, \Delta H^{0}\right.$ and $\left.\Delta S^{0}\right)$ of the adsorption of methylene blue onto Jatropha carbons were also obtained. The thermal activated carbon (JAC-3) was more effective for MB dye removal compared to chemical (JAC-2) and parent (JAC-1) activated carbon.
\end{abstract}

(c) 2011 Taiwan Institute of Chemical Engineers. Published by Elsevier B.V. All rights reserved.

\section{Introduction}

The textile and dye manufacturing industries play a significant role in the economy growth of Indonesia. Wastewater from these industries contain considerable amount of unused dyes, which are not readily biodegradable in natural environment. The direct discharge of colored wastewater from these kinds of industries into the aquatic streams harm the environment due to its toxicity and ability to impede the transmission of sunlight, retards photosynthesis activity by plant and phytoplankton, and inhibits the growth of biota and harm the stability of food web (Gad and El-Sayed, 2009). Additionally, most of synthetic dyes are very harmful to human life due to their acute and chronic effects. It is obvious that dyes are hazardous material hence their removal from industrial effluent is considered as an important step in the environmental protection.

A number of treatment methods are available for dyes removal such as coagulation, oxidation, biodegradation, photolysis, filtration and adsorption (Fernandez et al., 2010). Among them, adsorption is generally considered as an effective method for reducing the concentration of dissolved dyes in industrial wastewater. Since adsorption process is widely known as promising technique, which produces treated dye effluents with

\footnotetext{
* Corresponding author. Tel.: +62 313891164; fax: +62 313891167.

E-mail addresses: suryadiismadji@yahoo.com, suryadi@mail.wima.ac.id (S. Ismadji).
}

very low concentration, therefore in the past few years, the hundreds of studies have been conducted to develop different kind of cost effective/low cost adsorbents (Bhatnagar and Sillanpaa, 2010). In this regard, activated carbons have been developed extensively for the removal of different classes of dyes such as acid, direct, basic, reactive, disperse, sulphur and metallic.

Activated carbon is a versatile adsorbent from an industrial view of point due to its high adsorptive properties. It has complex nature and various surface properties with pore sizes ranging from micropores ( $<20 \AA$ slit width) to macropores ( $>500 \AA$ slit width). However, the large scale use of activated carbon in industrial wastewater treatment still limited due to its high cost. A method to overcome this limitation is by using agricultural or forestry wastes as precursor for activated carbon preparation, such as bagasse pith (Gad and El-Sayed, 2009), cashew nut shell (Kumar et al., 2011), rice straw (Fierro et al., 2010), cherry stones (Jaramillo et al., 2010), oak cups pulp (Timur et al., 2010), flower (Nethaji et al., 2010) and also various biodiesel solid residues (Foo and Hameed, 2009; Karagoz et al., 2008; Nunes et al., 2009).

Jatropha curcas $L$. press-cake residue is one of promising biomass wastes that can be utilized as precursor for active carbon preparation. Their seeds contain high enough oil and have been widely used for biodiesel production in several Asia countries. However, the solid residues that produced after seed-pressing process just ended as mere waste. In Indonesia, approximately $2,105,400$ tons of $J$. curcas $L$. seeds were produced in 2009 and $70 \%$ of it end up as solid residue. Accumulation of these wastes for long period of time often create environmental problem due to its 
unpleasant odor. Since the fixed carbon content in Jatropha presscake residue is quite high, hence the utilization of this waste as activated carbon precursor can minimize the environmental problem. To the best of our knowledge, to the present, there is no information about the preparation and modification of activated carbon from $J$. curcas $L$. press-cake residue available in the literature. The main objective of this present study is to develop low cost activated carbon from Jatropha waste and to investigate its adsorption performance for basic dye (methylene blue) removal from aqueous solution.

\section{Materials and methods}

\subsection{Activated carbon preparation}

$J$. curcas $L$. press-cake residue was used as activated carbon precursor in this study. Prior to used, the biomass was washed several times with tap water to remove physical impurities then dried in oven for overnight at $120^{\circ} \mathrm{C}$. Subsequently, the dry biomass was crushed into powder using microhammer mill and sieved to particle size fraction of 38-106 $\mu \mathrm{m}$.

The preparation of activated carbon was conducted by following procedure: $500 \mathrm{~g}$ of pretreated biomass were soaked in $\mathrm{KOH}$ solution for $24 \mathrm{~h}$ with impregnation ratio of $2: 1$. The choice of impregnation ratio 2:1 based on our preliminary experiments; at this impregnation ratio the pore structure of activated carbon was more developed than other impregnation ratio. The soaked biomass was then subjected to a two-step heating process at $120^{\circ} \mathrm{C}$ for $2 \mathrm{~h}$ in an oven and then at $500{ }^{\circ} \mathrm{C}$ for $4 \mathrm{~h}$ in a horizontal tubular furnace at a constant heating rate of $10{ }^{\circ} \mathrm{C} / \mathrm{min}$ under $\mathrm{N}_{2}$ stream at flow rate of $150 \mathrm{~cm}^{3} / \mathrm{min}$ (STP).

After carbonization process, the char that produced was cooled to room temperature under the same gaseous flow then rinsed with $0.5 \mathrm{~N} \mathrm{HCl}$ and hot distilled water until no significant change in $\mathrm{pH}$ detected. The char (JAC-1) was then dried in an oven at $120^{\circ} \mathrm{C}$ for $24 \mathrm{~h}$ and kept in dessicator for further use. The ultimate and proximate analysis of $J$. curcas $L$. press-cake residue and JAC- 1 was given in Table 1.

\subsection{Chemical and thermal activation of JAC-1}

Chemical activation of JAC-1 was conducted by following procedure (Huang et al., 2009): $50 \mathrm{~g}$ of JAC-1 was added into $500 \mathrm{~mL}$ round bottle flask containing $200 \mathrm{~mL}$ of concentrated nitric acid. The mixture was then heated at $80^{\circ} \mathrm{C}$ for $7 \mathrm{~h}$ under continuous stirring at $100 \mathrm{rpm}$. Subsequently, the oxidized carbon was rinsed with deionized water until no significant change in $\mathrm{pH}$ detected. Finally, the activated carbon sample was dried in an oven at $120^{\circ} \mathrm{C}$ for $24 \mathrm{~h}$ and kept in dessicator.

Thermal activation of JAC-1 was carried out in a horizontal tubular furnace (Thermolyne 21100) with the procedure as follows: $20 \mathrm{~g}$ of JAC-1 were placed in a stainless steel tubular

Table 1

Proximate and ultimate analysis of Jatropha press-cake residue and JAC-1.

\begin{tabular}{lcr}
\hline & Press-cake residue & JAC-1 \\
\hline Ultimate analysis (wt\%) & & \\
$\quad$ Carbon & 47.8 & 92.3 \\
Hydrogen & 6.7 & 1.2 \\
Nitrogen & 4.3 & 0.1 \\
$\quad$ Oxygen (*measured by difference) & 41.2 & 6.4 \\
Proximate analysis (wt\%) & & \\
$\quad$ Volatile matter & 50.9 & 2.3 \\
Fixed carbon & 39.2 & 86.6 \\
Ash & 2.6 & 11.1 \\
Moisture & 7.3 & - \\
\hline
\end{tabular}

reactor and heated from room temperature to $750{ }^{\circ} \mathrm{C}$ at a constant heating rate of $10^{\circ} \mathrm{C} / \mathrm{min}$ under $\mathrm{N}_{2}$ flow. Once the carbonization temperature was reached, the $\mathrm{N}_{2}$ flow was switched to air $\left(150 \mathrm{~cm}^{3} / \mathrm{min}\right)$ and maintained for $30 \mathrm{~min}$. The activated carbon sample was then cooled to room temperature under $\mathrm{N}_{2}$ flow and stored in dessicator. Here, chemical activation carbon and thermal activation carbon are referred as JAC-2 and JAC-3, respectively.

\subsection{Characterizations of active carbons}

The pore structure of JAC was analyzed by nitrogen sorption at $77 \mathrm{~K}$ using an automatic Micromeritics ASAP-2010 volumetric sorption analyzer. Prior to the gas adsorption measurements, the carbon samples were degassed at $573 \mathrm{~K}$ in a vacuum condition for a period of at least $24 \mathrm{~h}$. Nitrogen sorption isotherms were measured over a relative pressure $\left(P / P_{0}\right)$ range from approximately $10^{-5}$ to 0.995 .

The surface oxides of JAC were characterized by Boehm titration (Boehm, 2002). The Boehm titration is described as follow: $0.5 \mathrm{~g}$ of carbon sample was added to a series of conical flasks containing $50 \mathrm{~cm}^{3}$ of $0.05 \mathrm{M}$ : $\mathrm{NaOH}, \mathrm{Na}_{2} \mathrm{CO}_{3}, \mathrm{NaHCO}_{3}$ and $\mathrm{HCl}$ solutions. The conical flasks were then sealed and shaken for $24 \mathrm{~h}$ at room temperature. The solid suspension was decanted and $10 \mathrm{~cm}^{3}$ of the remaining solution was titrated with $0.05 \mathrm{M} \mathrm{HCl}$ or $\mathrm{NaOH}$, depends on the original solution used. The number of acidic groups was calculated under the assumptions that $\mathrm{NaOH}$ neutralizes carboxylic, phenolic and lactonic groups; $\mathrm{Na}_{2} \mathrm{CO}_{3}$ neutralizes carboxylic and lactonic groups; and $\mathrm{NaHCO}_{3}$ neutralizes only carboxylic groups. The number of basic sites presented on the carbon surface was determined from the amount of $\mathrm{HCl}$ reacted with sample.

The $\mathrm{pH}_{\mathrm{pzc}}$ of JAC was analyzed using $\mathrm{pH}$-drift technique (Faria et al., 2004). The $\mathrm{pH}$-drift procedure is described as follows: $50 \mathrm{~cm}^{3}$ of $0.01 \mathrm{~N} \mathrm{NaCl}$ solution was placed in several conical flasks. The $\mathrm{pH}$ was adjusted to value between 2 and 11 by adding $0.1 \mathrm{M} \mathrm{HCl}$ or $0.1 \mathrm{M} \mathrm{NaOH}$ solutions. After that, $0.15 \mathrm{~g}$ of carbon was added to the solution and the final pH was measured after $48 \mathrm{~h}$ (using digital $\mathrm{pH}$ meter Schott CG-825) under agitation at room temperature.

The surface functional groups of JAC were also characterized using infrared spectroscopy (FTIR SHIMADZU 8400S). This qualitative analysis was performed using $\mathrm{KBr}$ pelleting technique and all of the carbon spectra were recorded in mid-IR wave number range $\left(500-4000 \mathrm{~cm}^{-1}\right)$.

\subsection{Adsorption experiments}

Methylene blue (Basic Blue 9; C.I. 52015; chemical formula $\mathrm{C}_{16} \mathrm{H}_{18} \mathrm{~N}_{3} \mathrm{SCl} .3 \mathrm{H}_{2} \mathrm{O}$; $\mathrm{MW}: 373.90 \mathrm{~g} \mathrm{~mol}^{-1}$ ) was used as adsorbate in this study. It was purchased from Sigma-Aldrich as analytical reagent grade and directly used without any further treatment. The maximum wavelength of this dye is $664.1 \mathrm{~nm}$. The dye stock solution was prepared by dissolving a fixed amount of methylene blue into $1 \mathrm{~L}$ of deionized water. To prevent the decolorization by direct sunlight, the dye stock solution was stored in dark bottle and kept in dark place before used.

Adsorption equilibrium and kinetic studies were carried out in batch system. Adsorption equilibrium data were obtained by adding various mass of carbon (0.1-1.1 g) into a series of $250 \mathrm{~mL}$ conical flasks, containing $100 \mathrm{~mL}$ of dye solution with initial concentration of $1000 \mathrm{mg} / \mathrm{L}$. The conical flasks were then covered with aluminum foil, placed in thermostat shaker (MEMMERT) and shaken with constant speed at desired operating temperature until equilibrium state was achieved. Product analysis showed that the equilibrium state was achieved within 6-10 h. After equilibrium time reached, the dye solution was centrifuged at $4000 \mathrm{rpm}$ for 5 min (MLW T.51.1) to remove solid particles. The supernatant was then carefully taken and measured its residual dye concentration 
by UV/vis spectrophotometer (SHIMADZU UV/VIS-1700 PharmaSpec). The $\mathrm{pH}$ of dye solution was also measured at the start and at the end of each experiment using digital pH-meter (Schott CG-825) to check for any drift. The results indicated that no significant change in $\mathrm{pH}$ was detected in all experiments. Isotherm experiments were conducted at various $\mathrm{pH}(3,7$ and 11) and temperatures $\left(30^{\circ} \mathrm{C}, 45^{\circ} \mathrm{C}\right.$ and $\left.60^{\circ} \mathrm{C}\right)$. To adjust the $\mathrm{pH}$, an appropriate amount of $0.1 \mathrm{M} \mathrm{NaOH}$ or $0.1 \mathrm{M} \mathrm{HCl}$ solutions were added to the system.

Adsorption kinetic experiments were performed in glass vessel of $11 \mathrm{~cm}$ in inner diameter, $15 \mathrm{~cm}$ in height and fitted with four glass baffles $(1 \mathrm{~cm}$ in width). The dye solution was prepared by mixing a known amount of MB dye with deionized water to yield various initial concentrations of 200,500 and $800 \mathrm{mg} / \mathrm{L}$. Prior to the addition of carbon $(0.6 \mathrm{~g})$, the glass vessel containing $500 \mathrm{~mL}$ of dye solution was placed in the thermostat water-bath at $30^{\circ} \mathrm{C}$. The mixture was then agitated at $500 \mathrm{rpm}$ for $7 \mathrm{~h}$. During the experiments, at predetermined interval of time, the dye solution was taken from the vessel ( $1 \mathrm{~mL}$ using micropipette), diluted with deionized water, centrifuged and analyzed its residual dye concentration spectrophotometrically. All of adsorption experiments in this study were conducted in triplicate and the experimental results were given as averages.

The following equation was used to calculate the amount of MB dye adsorbed at equilibrium and at a certain time $t$ :

$q_{\mathrm{e}}=\frac{C_{0}-C_{\mathrm{e}}}{m} \times V$

$q_{t}=\frac{C_{0}-C_{t}}{m} \times V$

where $q_{\mathrm{e}}$ and $q_{t}$ is the amount of dye adsorbed at equilibrium and at a certain time $t(\mathrm{mg} / \mathrm{g}), C_{0}$ and $C_{\mathrm{e}}$ are the initial and equilibrium dye concentration in liquid phase $(\mathrm{mg} / \mathrm{L})$, respectively, $m$ is the amount of adsorbent used (g) and $V$ is the volume of dye solution (L).

\section{Results and discussion}

\subsection{Textural characterizations of active carbons}

The physical characteristics of the adsorbent are related to the pore structure of adsorbent such as micropore surface area $\left(S_{\text {micro }}\right)$, mesopore surface area $\left(S_{\text {meso }}\right)$, micropore volume $\left(V_{\text {micro }}\right)$, and specific surface area $\left(S_{\mathrm{BET}}\right)$. The pore structure of JAC was analyzed by nitrogen sorption technique. The specific BET surface area $\left(S_{\mathrm{BET}}\right)$, micropore volume $\left(V_{\text {micro }}\right)$ and micropore surface area $\left(S_{\text {micro }}\right)$ was determined by application of the Brunauer-Emmett-Teller (BET) and Dubinin-Asthakov (DA) analysis software available within the instrument, respectively. The specific BET surface area of JAC was determined by means of the standard BET equation applied in the relative pressure range from 0.06 to 0.3 while for the micropore volume $\left(V_{\text {micro }}\right)$ and micropore surface area $\left(S_{\text {micro }}\right)$ were determined by application of the $t$-plot method on the adsorption isotherm. The values of physical characteristic of JAC carbons are given in Table 2. The pore size distribution of JAC was determined from adsorption isotherm data using the Density Functional

Table 2

Physical properties of JAC.

\begin{tabular}{lllll}
\hline \multirow{2}{*}{ Active carbon } & \multicolumn{4}{l}{ Surface characteristic } \\
\cline { 2 - 5 } & $S_{\text {BET }}\left(\mathrm{m}^{2} / \mathrm{g}\right)$ & $S_{\text {micro }}\left(\mathrm{m}^{2} / \mathrm{g}\right)$ & $S_{\text {meso }}\left(\mathrm{m}^{2} / \mathrm{g}\right)$ & $V_{\text {micro }}\left(\mathrm{cm}^{3} / \mathrm{g}\right)$ \\
\hline JAC-1 & 845.55 & 761.81 & 83.74 & 0.396 \\
JAC-2 & 792.23 & 714.32 & 77.91 & 0.374 \\
JAC-3 & 904.72 & 817.19 & 87.53 & 0.427 \\
\hline
\end{tabular}

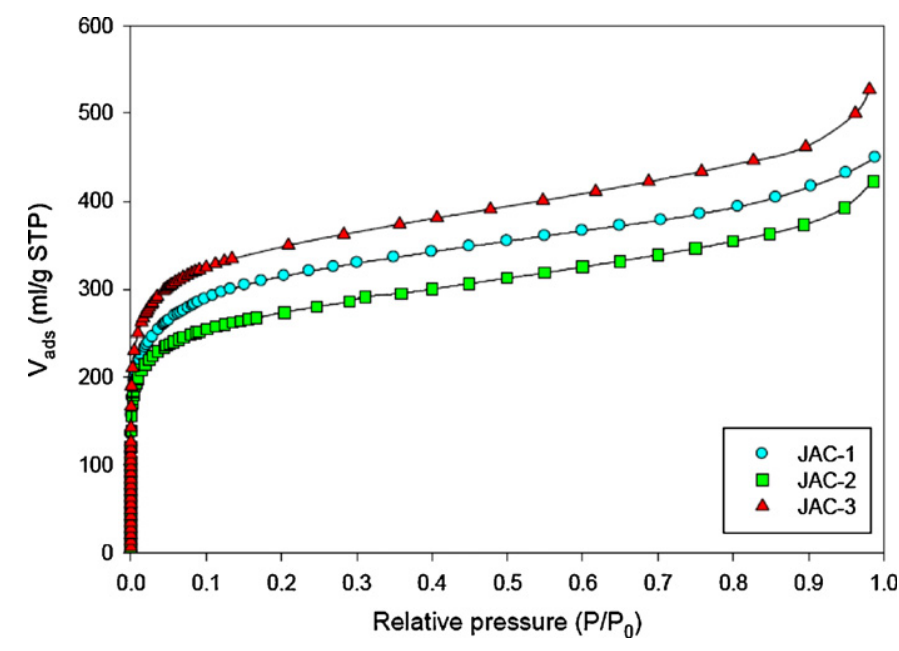

Fig. 1. Nitrogen sorption isotherms of JAC.

Theory (DFT) software with medium regularization. Nitrogen sorption results (Fig. 1) show the largely microporous nature of the carbons, with some mesopores leading to gradual increase in the adsorption after the initial filling of the micropores, followed by rapid increase near saturation. This statement was also supported by DFT results (Fig. 2), which showed that all JAC exhibited several peaks at pore width ranging from 5 to $30 \AA$.

Chemical treatment on activated carbon using various oxidizing agents such as $\mathrm{HNO}_{3}, \mathrm{H}_{2} \mathrm{O}_{2}, \mathrm{Fe}\left(\mathrm{NO}_{3}\right)_{3},\left(\mathrm{NH}_{4}\right)_{2} \mathrm{~S}_{2} \mathrm{O}_{8}$, etc. can increase the amount of acidic surface groups, mainly carboxylic acid and also anhydrides, lactone and phenol groups in less extent. Among them, chemical treatment by $\mathrm{HNO}_{3}$ is generally considered as the most effective method to increase the acidic groups on carbon surface (Faria et al., 2004). The acidic groups, specifically carboxylic acids are known to be the binding sites for basic dyes such as methylene blue hence the presence of this group can improve the adsorption capacity of activated carbon. It was also known that chemical (wet) oxidation can reduce the surface area of carbon (JAC-2) due to the presence of numerous oxygenated groups that partially blocked the access of $\mathrm{N}_{2}$ molecules to the small pores. Moreover, oxidation of carbon by $\mathrm{HNO}_{3}$ also caused nitration attack by nitronium ions $\left(\mathrm{NO}_{2}{ }^{+}\right)$on the polyaromatic sheets. The nitronium ion is a strong electrophile (Lewis acid), which can substitute hydrogen atom in aromatic ring based on electrophilic aromatic substitution mechanism (Draper and Ridd, 1978).

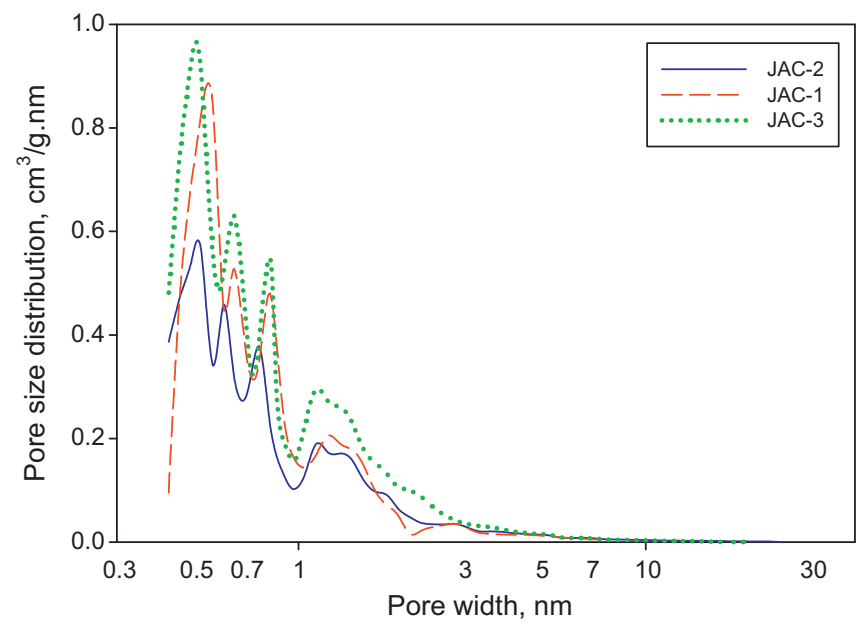

Fig. 2. Pore size distribution of JAC. 
In thermal treatment, most of the oxygenated groups on carbon surface (carboxylic acid, lactone and phenol) were decomposed to $\mathrm{CO}_{2}$ and $\mathrm{CO}$ at high temperature carbonization, resulting in the extension of carbon surface area and the generation of large amounts of reactive sites on the carbon basal planes which have electron rich oxygen free-radical character (Leon et al., 1992). These reactive sites reacted with oxygen contained in the air thus producing new surface oxides, which can be assigned to carbonyl, pyrone or chromene type structures. These surface groups have basic surface properties, corresponding to the basic nature of JAC3. By comparing nitrogen sorption and pore size distribution results of all JAC that have similar characteristic, it is obvious that both chemical and thermal treatment gave insignificant effect on the textural properties hence the adsorption capacity of JAC for MB dye removal will also depend on their surface chemistry properties.

\subsection{Surface chemistry characterization of active carbons}

The surface functional groups of JAC were analyzed by FTIR spectroscopy. The analysis results showed that several major peaks on JAC-1 was appeared at the following wave numbers: $805 \mathrm{~cm}^{-1}$ attributed to $\mathrm{O}-\mathrm{H}$ stretch in out-of-plane bending; $1176 \mathrm{~cm}^{-1}$ related to the $\mathrm{C}=\mathrm{O}$ stretch in lactone; $1589 \mathrm{~cm}^{-1}$ associated to $\mathrm{C}=\mathrm{C}$ stretch in aromatic skeletal; $1729 \mathrm{~cm}^{-1}$ attributed to $\mathrm{C}=0$ stretch in carboxylic acid; $2945 \mathrm{~cm}^{-1}$ ascribed to the presence of symmetric $\mathrm{C}-\mathrm{H}$ stretch in methylene $\left(-\mathrm{CH}_{2}\right)$ groups; $3021 \mathrm{~cm}^{-1}$ revealed to $\mathrm{C}-\mathrm{H}$ stretch in aromatic ring and the last peak at $3440 \mathrm{~cm}^{-1}$ contributed to the presence of $\mathrm{O}-\mathrm{H}$ stretch in phenolic groups.

The intensity of some peaks in JAC-2 spectra that are characteristic of $\mathrm{C}=\mathrm{O}$ functional groups at wave number of $1730 \mathrm{~cm}^{-1}$ (carboxylic acid), $1177 \mathrm{~cm}^{-1}$ (lactone) and $3400 \mathrm{~cm}^{-1}$ (phenol) increased during chemical oxidation by $\mathrm{HNO}_{3}$. New peak was also observed at wave number of $1600 \mathrm{~cm}^{-1}$, which assigned to the nitro groups as the result of nitration attack by $\mathrm{NO}_{2}{ }^{+}$ions on the aromatic ring groups in carbon skeletal.

The FTIR spectra of JAC-3 reflected similar characteristic with JAC-1, denoting that JAC-3 carbon had essentially the same species of surface groups except for the new peak assignment that appeared at wave number of $1582 \mathrm{~cm}^{-1}$. This peak may assign to carbonyl or quinone groups, which have basic surface nature (Lewis basicity). Furthermore, the decrease in intensity of several peaks that attributed to carboxylic acid, phenol and lactone was also noticed due to the decomposition of these oxygenated groups during carbonization process at $750{ }^{\circ} \mathrm{C}$. The surface oxides of JAC carbons obtained by Boehm titration are summarized in Table 3.

\subsection{Chemisorption mechanisms of $M B$ dye onto JAC}

In order to investigate the dominant mechanism that may occur in the adsorption of methylene blue, some information relating to adsorbent nature and $\mathrm{pH}$ must be imparted. It is known that $\mathrm{pH}$ is one of key parameter in the adsorption study as it affects the chemistry of the solution, the ionic species of adsorbate as well as the surface charge density of adsorbent. In this study, the chemisorption mechanisms of MB dye onto JAC were proposed using molecular modeling by ChemDraw software package (Fig. 3).

At $\mathrm{pH} 3\left(\mathrm{pH}<\mathrm{pH}_{\mathrm{pzc}}\right)$, the surface all of JAC were influenced mainly by positive charge due to the excessive protonation on the carbon basal planes through electrostatic interaction with the $\pi$ electrons of the graphene layers (Montes-Moran et al., 2004). As the carbon surface exhibited positive charge, the MB dye existed in triple protonated form (Khalid, 2001). Under this condition, the dye uptake was limited by repulsion forces which occurred between MB dye cations and positively charged of carbon surface. Electrostatic interaction also existed between $\mathrm{MB}$ dye cations and carboxylate anions $\left(\mathrm{COO}^{-}\right)$on the JAC surface, however, this interaction much weaker compared to the repulsion forces resulting low dye uptake in this $\mathrm{pH}$ value.

The carboxylic groups on JAC surface were in the order of JAC$2>$ JAC- $1>$ JAC- 3 , in which the MB dye uptake must follows this order. It is also known that carboxylic groups can dissociate in water when the $\mathrm{pH}$ of the system lies between 2 and 6 , resulting in the formation of carboxylate anions. The carboxylate anions are known to be the active binding sites for basic dyes such as methylene blue hence the presence of this group enhanced the dye uptake. However, the inconsistency in the experimental results was observed (JAC-3 > JAC-2 > JAC-1), an indication that another interaction may also took place during dye adsorption process.

The high dye uptake by JAC-3 (basic nature carbon) due to the existence of two parallel mechanisms: electrostatic and dispersive interactions. The latter interaction was occurred between the delocalized $\pi$-electrons on the carbon basal planes and the free electrons of dye molecules present in the aromatic rings or multiple bonds $(-\mathrm{N}=\mathrm{C}-\mathrm{C}=\mathrm{C}-$ ). This interaction played a dominant role in the adsorption process of methylene blue on JAC-3. The pore characteristic of JAC-3 also contributes a significant role in the dye removal due to the enlargement in the micropores and mesopores structures as a result of the decomposition of surface oxygenated groups during heat treatment.

Low dye uptake by JAC-2 (acid nature carbon) suggests that other interaction such as water bonding and electrostatic repulsion may also play an important role in the adsorption process. It was reported that water molecules can bind into acidic surface oxides, especially carboxylic groups through $\mathrm{H}$-bonding (Coughlin and Ezra, 1968) hence the presence of this group could reduce the amount of dye uptake due to the blockade on the micropores region by water. Chemical oxidation on carbon using $\mathrm{HNO}_{3}$ also gave a negative effect on the dye uptake due to the insertion of nitrogen functionalities $\left(\mathrm{NO}_{2}\right)$ which provides more positive surface sites. The presence of abundant positive surface sites increased the repulsion forces therefore less molecules dye adsorbed in the surface of carbon. Higher dye by JAC-2 compared to JAC-1 (parent carbon) may correspond to the stronger effect of electrostatic interaction of carboxylate anions and MB molecules. As mentioned before, the JAC-2 possesses more carboxylics groups than JAC-1, therefore more carboxylate anions are available on the JAC-2 surface. In addition, low dye uptake at $\mathrm{pH} 3$ was also caused by the competition between protons $\left(\mathrm{H}^{+}\right)$and $\mathrm{MB}$ dye cations in bulk solution onto the active binding sites on carbon surface.

In neutral $\mathrm{pH}$, the JAC-2 surface is predominated by negative charge $\left(\mathrm{pH}>\mathrm{pH}_{\mathrm{pzc}}\right)$ while for JAC-1 and JAC-3, the overall charge

Table 3

Surface chemistry of JAC.

\begin{tabular}{lclllll}
\hline Active carbon & $\mathrm{pH}_{\mathrm{pzc}}$ & $\begin{array}{l}\text { Carboxylic } \\
\text { (mequiv./g) }\end{array}$ & $\begin{array}{l}\text { Lactone } \\
\text { (mequiv./g) }\end{array}$ & $\begin{array}{l}\text { Phenol } \\
\text { (mequiv./g) }\end{array}$ & $\begin{array}{l}\text { Acidity } \\
\text { (mequiv./g) }\end{array}$ & $\begin{array}{l}\text { Basicity groups } \\
\text { (mequiv./g) }\end{array}$ \\
\hline JAC-1 & 8.2 & 0.143 & 0.095 & 0.109 & 0.347 & 0.521 \\
JAC-2 & 3.7 & 0.372 & 0.157 & 0.264 & 0.793 & 0.214 \\
JAC-3 & 10.1 & 0.061 & 0.012 & 0.043 & 0.116 & 0.817 \\
\hline
\end{tabular}




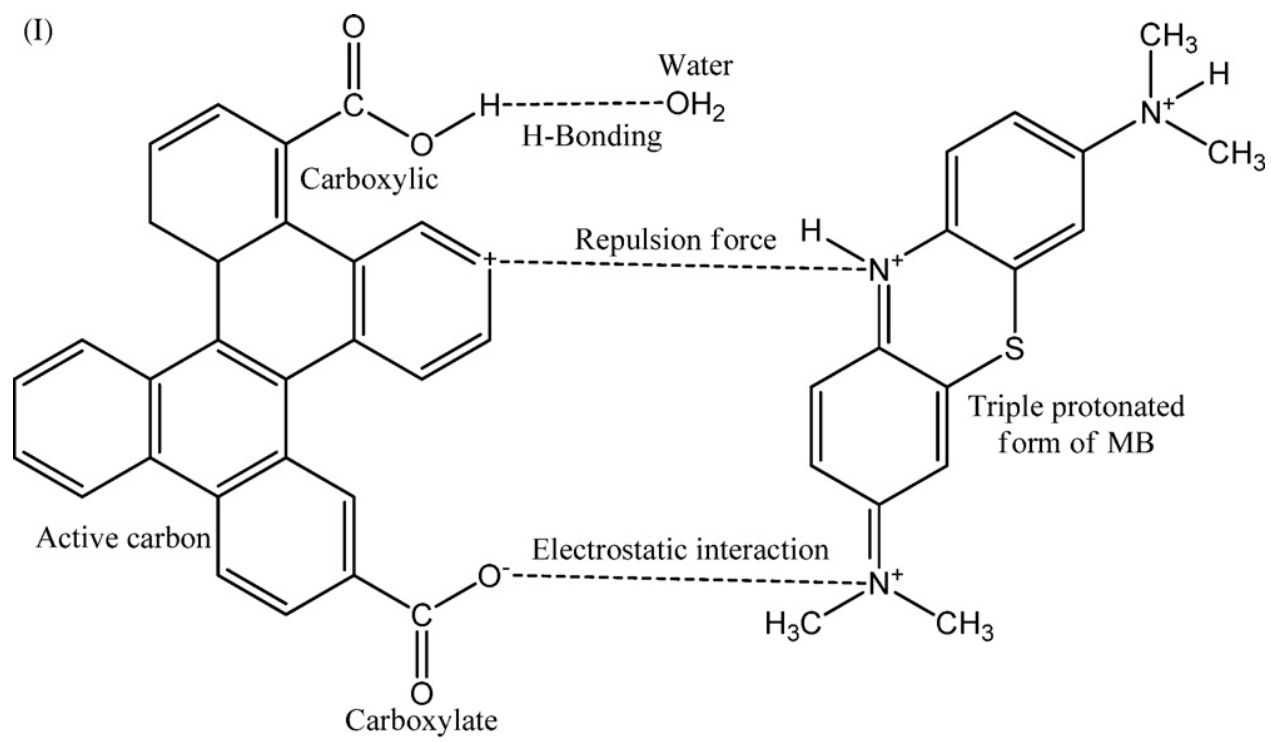<smiles>CN(C)c1ccc([N+](C)(C)C)cc2cc(=[N+](C)C)cc3sc(cc1)nc3-2</smiles>

Fig. 3. Chemisorption mechanism of MB dye onto JAC at $\mathrm{pH} 3$ (I) and $\mathrm{pH} 11$ (II).

on their surface is positive $\left(\mathrm{pH}_{\mathrm{pzc}}>\mathrm{pH}\right)$. As given in Fig. 4 , the dye uptake at $\mathrm{pH} 7$ are in the order of JAC-3 $>$ JAC- $2>$ JAC- 1 , indicates the mechanisms involved in the adsorption of dye in $\mathrm{pH} 7$ are similar with $\mathrm{pH}$ 3. The dye uptake at $\mathrm{pH} 7$ was higher than $\mathrm{pH}$ 3. At $\mathrm{pH} 7$, the presence of protons $\left(\mathrm{H}^{+}\right)$in the solution was much less than at $\mathrm{pH} 3$, therefore less competition between protons $\left(\mathrm{H}^{+}\right)$and MB dye cations in bulk solution onto the active binding sites on carbon surface occurred.

In basic solution ( $\mathrm{pH} 11)$, the surface of all JAC were predominated by negative surface sites due to $\mathrm{pH}>\mathrm{pH}_{\mathrm{pzc}}$ and the dissociation of phenol groups on carbon surface occurred, leading to the formation of phenolate anions, while MB dye existed in single protonated form. In this case, the MB dye uptake onto JAC caused by the electrostatic interaction between negatively charged on the carbon surface and dye cations. Another interaction, the $\pi-$ $\pi$ dispersion, may also take place during adsorption of dye. This interaction was generated between the $\pi$-electrons on carbon basal planes and the $\pi$-electrons on aromatic rings of dye molecules. Furthermore, the excessive presence of hydroxyl groups $\left(\mathrm{OH}^{-}\right)$in bulk solution also gives a positive effect on the $\pi-\pi$ dispersion interaction, which increased the $\pi$-electron density on carbon basal planes, hence enhanced the adsorption of MB dye. Highest dye uptake at pH 11 compared with other systems ( $\mathrm{pH} 3$ and $\mathrm{pH} 7$ ) due to the existence of two parallel mechanisms, the $\pi-\pi$ dispersion and electrostatic interaction.

\subsection{Adsorption isotherms}

Equilibrium relationship between adsorbate and adsorbent can be determined by adsorption isotherm study, which describes how the adsorbate molecules distribute between the liquid phase and the solid phase when the adsorption reaches equilibrium. Various adsorption isotherm models for the gas phase adsorption such as Langmuir, Freundlich, Toth, Sips, etc., can in principle be extended to liquid phase adsorption. Among these isotherms, the Langmuir and the Freundlich isotherm are the most widely used models to represent the liquid phase adsorption experimental data (Ai et al., 2010; Demirbas et al., 2009; Liu et al., 2011). The Langmuir isotherm is expressed as follows:

$q_{\mathrm{e}}=q_{\max } \frac{K_{\mathrm{L}} C_{\mathrm{e}}}{1+K_{\mathrm{L}} C_{\mathrm{e}}}$

where $q_{\max }$ and $K_{\mathrm{L}}$ are the Langmuir parameters corresponded to the maximum adsorption capacity for specific adsorbent $(\mathrm{mg} / \mathrm{g}$ ) and the equilibrium constant $(\mathrm{L} / \mathrm{mg})$, respectively. The essential characteristic of the Langmuir isotherm can be expressed by 

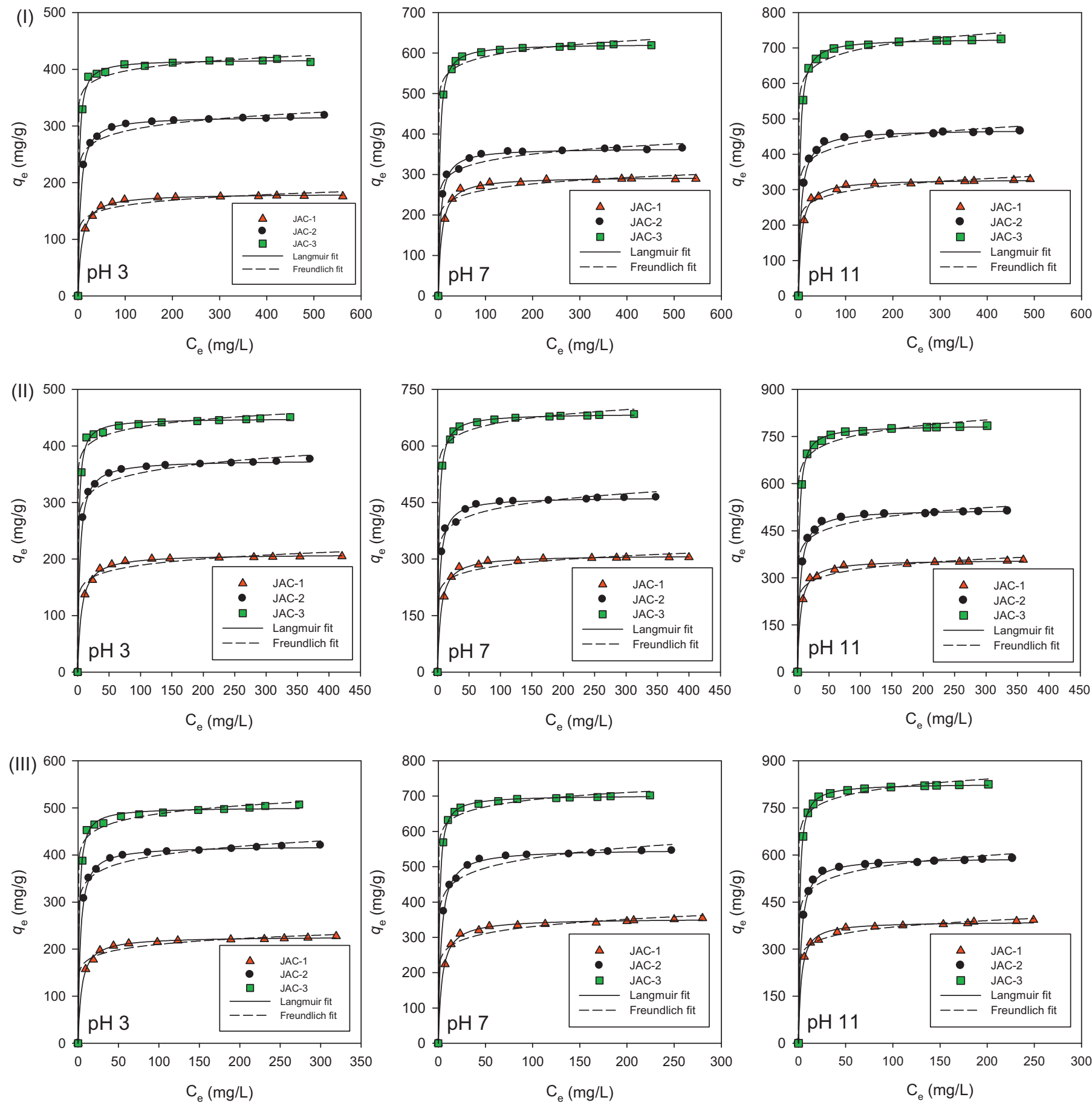

Fig. 4. Isotherm plots of $\mathrm{MB}$ dye uptake onto JAC at $30^{\circ} \mathrm{C}$ (I), $45^{\circ} \mathrm{C}$ (II) and $60{ }^{\circ} \mathrm{C}$ (III).

dimensionless constant called equilibrium parameter, $R_{\mathrm{L}}$, which defined by following equation:

$R_{\mathrm{L}}=\frac{1}{1+K_{\mathrm{L}} C_{0}}$

The value of $R_{\mathrm{L}}$ indicates the various nature of isotherm to be irreversible $\left(R_{\mathrm{L}}=0\right)$, favorable $\left(0<R_{\mathrm{L}}<1\right)$, linear $\left(R_{\mathrm{L}}=1\right)$ or unfavorable $\left(R_{\mathrm{L}}>1\right)$.

Another empirical isotherm model that widely used to represent equilibrium data is Freundlich model, which has the form:

$$
q_{\mathrm{e}}=K_{\mathrm{F}} \times C_{\mathrm{e}}^{1 / n}
$$

where $K_{\mathrm{F}}$ and $n$ are the Freundlich parameters represented the adsorption affinity $\left[(\mathrm{mg} / \mathrm{g})(\mathrm{L} / \mathrm{mg})^{1 / n}\right]$ and the heterogeneity of the system, respectively.

The isotherm plots of Langmuir and Freundlich models at various $\mathrm{pH}$ and temperatures are given in Fig. 4. As shown in this figure, Langmuir model could represent the experimental data better $\left(R^{2}>0.99\right)$ than Freundlich equation. The parameters of 
Table 4

Isotherm model parameters for MB dye adsorption onto JAC.

\begin{tabular}{|c|c|c|c|c|c|c|c|c|c|c|c|c|c|c|}
\hline \multirow{2}{*}{$\begin{array}{l}\text { Active } \\
\text { carbon }\end{array}$} & \multirow{2}{*}{$\begin{array}{l}\text { Isotherm } \\
\text { model }\end{array}$} & \multirow[t]{2}{*}{ Parameter } & \multirow[t]{2}{*}{$\mathrm{pH}$} & \multicolumn{3}{|l|}{$T(\mathrm{~K})$} & \multirow[t]{2}{*}{$\mathrm{pH}$} & \multicolumn{3}{|l|}{$T(\mathrm{~K})$} & \multirow[t]{2}{*}{$\mathrm{pH}$} & \multicolumn{3}{|l|}{$T(\mathrm{~K})$} \\
\hline & & & & 303.15 & 318.15 & 333.15 & & 303.15 & 318.15 & 333.15 & & 303.15 & 318.15 & 333.15 \\
\hline \multirow[t]{7}{*}{ JAC-1 } & \multirow[t]{4}{*}{ Langmuir } & $K_{\mathrm{L}}(\mathrm{L} / \mathrm{mg})$ & \multirow[t]{21}{*}{3} & 1.8854 & 2.8219 & 3.7501 & \multirow[t]{21}{*}{7} & 2.6365 & 4.1524 & 5.1971 & \multirow[t]{21}{*}{11} & 3.5549 & 5.1832 & 7.2228 \\
\hline & & $q_{\max }(\mathrm{mg} / \mathrm{g})$ & & 177.92 & 206.73 & 230.51 & & 292.05 & 306.63 & 357.59 & & 327.56 & 359.11 & 393.06 \\
\hline & & $R_{\mathrm{L}}$ & & 0.0078 & 0.0059 & 0.0044 & & 0.0070 & 0.0052 & 0.0039 & & 0.0063 & 0.0046 & 0.0028 \\
\hline & & $R^{2}$ & & 0.9987 & 0.9984 & 0.9982 & & 0.9980 & 0.9982 & 0.9978 & & 0.9982 & 0.9989 & 0.9963 \\
\hline & \multirow[t]{3}{*}{ Freundlich } & $K_{\mathrm{F}}\left[(\mathrm{mg} / \mathrm{g})(\mathrm{mg} / \mathrm{L})^{-1 / \mathrm{n}}\right]$ & & 111.42 & 128.89 & 144.37 & & 182.70 & 195.11 & 219.72 & & 201.11 & 221.94 & 257.55 \\
\hline & & $n$ & & 0.0798 & 0.1567 & 0.3312 & & 0.0688 & 0.1241 & 0.3154 & & 0.0835 & 0.1552 & 0.3461 \\
\hline & & $R^{2}$ & & 0.9731 & 0.9735 & 0.9850 & & 0.9717 & 0.9722 & 0.9761 & & 0.9799 & 0.9749 & 0.9918 \\
\hline \multirow[t]{7}{*}{ JAC-2 } & \multirow[t]{4}{*}{ Langmuir } & $K_{\mathrm{L}}(\mathrm{L} / \mathrm{mg})$ & & 2.2149 & 3.2861 & 4.6307 & & 2.8537 & 4.0663 & 5.9347 & & 3.6859 & 5.5241 & 7.5831 \\
\hline & & $q_{\max }(\mathrm{mg} / \mathrm{g})$ & & 317.63 & 379.52 & 424.42 & & 366.76 & 467.19 & 546.93 & & 469.36 & 515.45 & 590.65 \\
\hline & & $R_{\mathrm{L}}$ & & 0.0047 & 0.0033 & 0.0027 & & 0.0048 & 0.0032 & 0.0029 & & 0.0054 & 0.0039 & 0.0025 \\
\hline & & $R^{2}$ & & 0.9995 & 0.9996 & 0.9994 & & 0.9965 & 0.9968 & 0.9991 & & 0.9994 & 0.9996 & 0.9994 \\
\hline & \multirow[t]{3}{*}{ Freundlich } & $K_{\mathrm{F}}\left[(\mathrm{mg} / \mathrm{g})(\mathrm{mg} / \mathrm{L})^{-1 / n}\right]$ & & 217.09 & 260.24 & 293.24 & & 234.71 & 307.60 & 364.44 & & 302.36 & 340.03 & 406.39 \\
\hline & & $n$ & & 0.0643 & 0.1458 & 0.3126 & & 0.0570 & 0.1135 & 0.3083 & & 0.0646 & 0.1462 & 0.3282 \\
\hline & & $R^{2}$ & & 0.9884 & 0.9880 & 0.9895 & & 0.9824 & 0.9828 & 0.9822 & & 0.9793 & 0.9794 & 0.9814 \\
\hline \multirow[t]{7}{*}{ JAC-3 } & \multirow[t]{4}{*}{ Langmuir } & $K_{\mathrm{L}}(\mathrm{L} / \mathrm{mg})$ & & 2.8564 & 4.5264 & 6.2962 & & 3.6321 & 5.7313 & 7.7755 & & 5.1553 & 7.1871 & 9.6732 \\
\hline & & $q_{\max }(\mathrm{mg} / \mathrm{g})$ & & 419.75 & 453.26 & 510.32 & & 624.55 & 685.49 & 706.88 & & 730.34 & 785.33 & 827.34 \\
\hline & & $R_{\mathrm{L}}$ & & 0.0023 & 0.0016 & 0.0015 & & 0.0028 & 0.0016 & 0.0012 & & 0.0030 & 0.0021 & 0.0012 \\
\hline & & $R^{2}$ & & 0.9987 & 0.9985 & 0.9977 & & 0.9998 & 0.9995 & 0.9998 & & 0.9997 & 0.9990 & 0.9999 \\
\hline & \multirow[t]{3}{*}{ Freundlich } & $K_{\mathrm{F}}\left[(\mathrm{mg} / \mathrm{g})(\mathrm{mg} / \mathrm{L})^{-1 / n}\right]$ & & 321.75 & 355.83 & 388.49 & & 475.24 & 535.16 & 566.66 & & 531.55 & 589.73 & 657.94 \\
\hline & & $n$ & & 0.0640 & 0.1371 & 0.3014 & & 0.0561 & 0.1062 & 0.3004 & & 0.0563 & 0.1396 & 0.3218 \\
\hline & & $R^{2}$ & & 0.9895 & 0.9905 & 0.9914 & & 0.9926 & 0.9926 & 0.9936 & & 0.9895 & 0.9902 & 0.9924 \\
\hline
\end{tabular}

each model were obtained by non-linear regression method (Table 4 ). Based on the value of $R_{\mathrm{L}}\left(0<R_{\mathrm{L}}<1\right)$, all systems show favorable adsorption process. The value of parameters $K_{\mathrm{L}}$ and $q_{\max }$ in Langmuir model increased as the temperature increased. Similar trend was also observed in Freundlich model. The increase of these parameters with the increase of temperature indicated that the adsorption process of MB in JAC carbons was an endothermic process. Table 5 shows the comparison of the maximum adsorption capacity of various low cost and commercial active carbons for MB dye removal. The adsorption capacity of JAC-3 is higher than other adsorbents, indicates that JAC-3 is suitable as the adsorbent for dye removal from wastewater.

\subsection{Adsorption kinetics}

In the design of the adsorption system, the data obtained from the adsorption kinetic study are very important since it contain the information about the adsorption mechanism, the potential rate controlling steps, etc. This information is required to select the optimum condition for full scale batch metal removal processes. Several adsorption kinetic models have been developed to understand the adsorption kinetics and rate limiting step. The pseudo-first and second order kinetic models are well known models to correlate the adsorption dynamic or kinetic data for various systems. The pseudo-first order, which also known as Lagergren kinetic model (Lagergren, 1898) has the form:

$\frac{d q_{t}}{d t}=k_{1}\left(q_{\mathrm{e}}-q_{t}\right)$

Integrating Eq. (6) with the boundary conditions $t=0 \rightarrow t=t$ and $q_{t}=0 \rightarrow q_{t}=q_{t}$ gives:

$q_{t}=q_{\mathrm{e}}\left(1-\exp \left(-k_{1} t\right)\right)$

While the pseudo-second order model (Ho and McKay, 1999) can be expressed as:

$\frac{d q_{t}}{d t}=k_{2}\left(q_{\mathrm{e}}-q_{t}\right)^{2}$

Integrating Eq. (8) with the boundary condition: $t=0 \rightarrow t=t$ and $q_{t}=0 \rightarrow q_{t}=q_{t}$ gives

$q_{t}=q_{\mathrm{e}}\left(\frac{q_{\mathrm{e}} k_{2} t}{1+q_{\mathrm{e}} k_{2} t}\right)$

where $k_{1}$ and $k_{2}$ are the pseudo-first order $\left(\mathrm{min}^{-1}\right)$ and pseudosecond order $\left(\mathrm{g} \mathrm{mg}^{-1} \mathrm{~min}^{-1}\right)$ rate constants, respectively.

Table 5

Maximum adsorption capacity $\left(q_{\max }\right)$ of several adsorbents for MB dye removal.

\begin{tabular}{|c|c|c|}
\hline & $q_{\max }(\mathrm{mg} / \mathrm{g})$ & Reference \\
\hline \multicolumn{3}{|l|}{ Commercial active carbon } \\
\hline Filtrasorb 300 & 240 & Stavropoulos and Zabaniotou (2005) \\
\hline Filtrasorb 400 & 476 & El Qada et al. (2008) \\
\hline Norit & 276 & Raposo et al. (2009) \\
\hline Picacarb & 246 & Raposo et al. (2009) \\
\hline \multicolumn{3}{|l|}{ Biomass based - active carbon } \\
\hline Vetiver roots & $375-423$ & Altenor et al. (2009) \\
\hline Oak cups pulp & $384.6-454.5$ & Timur et al. (2010) \\
\hline Corncob hull & 684.24 & Wu et al. (2011) \\
\hline Bamboo & $195.8-618.5$ & Liu et al. (2011) \\
\hline Olive seed waste residue & $190-263$ & Stavropoulos and Zabaniotou (2005) \\
\hline Defective coffee press-cake residue & 14.9 & Nunes et al. (2009) \\
\hline Sunflower oil cake & 16.4 & Karagoz et al. (2008) \\
\hline JAC-1 & $177.9-393.0$ & This study \\
\hline JAC-2 & $317.6-590.6$ & This study \\
\hline JAC-3 & $419.7-827.3$ & This study \\
\hline
\end{tabular}



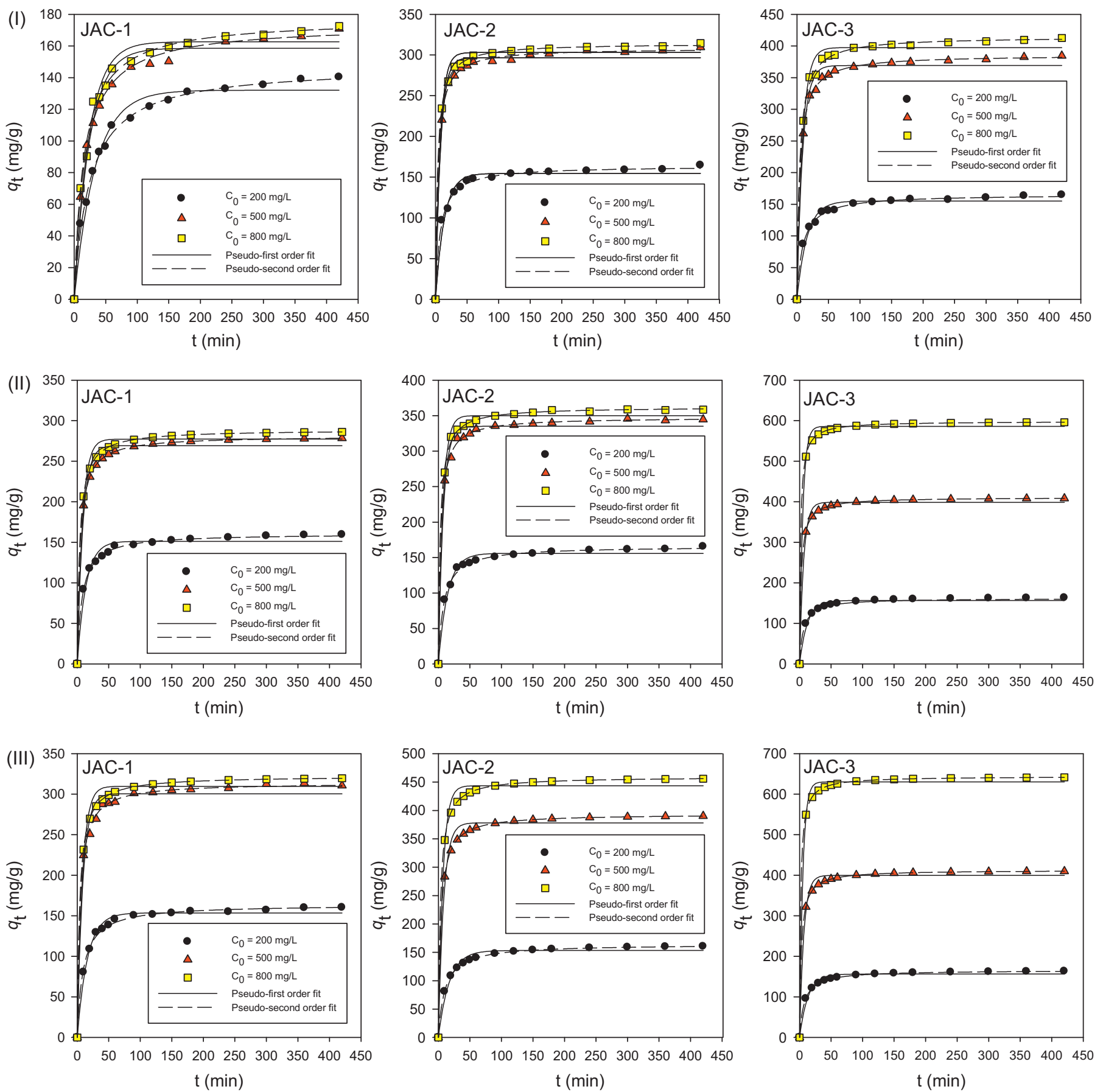

Fig. 5. Kinetic plots of pseudo-first order (Lagergren) and pseudo-second order model for MB dye uptake onto JAC at pH 3 (I), pH 7 (II) and pH 11 (III).

The adsorption kinetics data of MB in JAC carbons and the fitted models are depicted in Fig. 5, and the fitted kinetic parameters of pseudo-first order and pseudo-second order are summarized in Tables 6 and 7, respectively. In this figure, the kinetic plots are characterized by fast dye uptake and the sharp rise in solid phase concentration. By comparing the fitting result by pseudo first order and pseudo second order, the latter seems to give better representation. Additionally, the fitted parameter $q_{\mathrm{e}}$ in pseudosecond order agree quite well with the experimental data. The applicability of the pseudo-second order model to correlate the adsorption kinetic data of MB on JAC carbons suggested that the rate-controlling step in $\mathrm{MB}$ dye uptake onto JAC is chemisorption involving valence forces through the exchange or sharing of electrons between the adsorbate molecules and the surface functional groups of adsorbent.

\subsection{Thermodynamic aspects}

In order to gain complete understanding about the $M B$ adsorption onto JAC surface, the thermodynamic properties such as the change in standard Gibb's free energy $\left(\Delta G^{0}\right)$, enthalpy $\left(\Delta H^{0}\right)$ and entropy $\left(\Delta S^{0}\right)$ also have been investigated. The standard Gibb's free energy change was calculated by following equation:

$\Delta G^{0}=-R T \ln K_{\mathrm{D}}$ 
Table 6

Kinetic parameters of pseudo-first order for MB dye adsorption onto JAC.

\begin{tabular}{|c|c|c|c|c|c|c|c|c|c|}
\hline \multirow[t]{2}{*}{$C_{0}, \mathrm{mg} / \mathrm{L}$} & \multicolumn{3}{|l|}{ JAC-1 } & \multicolumn{3}{|l|}{ JAC-2 } & \multicolumn{3}{|l|}{ JAC-3 } \\
\hline & $k_{1}(1 / \mathrm{min})$ & $q_{e}(\mathrm{mg} / \mathrm{g})$ & $q_{e} \exp (\mathrm{mg} / \mathrm{g})$ & $k_{1}(1 / \mathrm{min})$ & $q_{e}(\mathrm{mg} / \mathrm{g})$ & $q_{e} \exp (\mathrm{mg} / \mathrm{g})$ & $k_{1}(1 / \mathrm{min})$ & $q_{e}(\mathrm{mg} / \mathrm{g})$ & $q_{e} \exp (\mathrm{mg} / \mathrm{g})$ \\
\hline \multicolumn{10}{|l|}{ pH 3} \\
\hline 200 & 0.0298 & 132.06 & 146.33 & 0.0624 & 154.52 & 163.21 & 0.0724 & 155.07 & 164.65 \\
\hline 500 & 0.0410 & 158.57 & 173.92 & 0.1097 & 296.60 & 307.29 & 0.1147 & 369.23 & 383.33 \\
\hline 800 & 0.0425 & 162.65 & 175.50 & 0.1116 & 303.08 & 313.68 & 0.1332 & 397.37 & 413.13 \\
\hline \multicolumn{10}{|l|}{$\mathrm{pH} 7$} \\
\hline 200 & 0.0680 & 151.32 & 160.85 & 0.0733 & 155.92 & 163.31 & 0.0817 & 156.61 & 165.61 \\
\hline 500 & 0.1306 & 269.25 & 281.28 & 0.1115 & 335.02 & 346.28 & 0.1567 & 398.82 & 411.06 \\
\hline 800 & 0.1385 & 277.33 & 288.93 & 0.1103 & 350.02 & 360.93 & 0.1964 & 586.17 & 598.80 \\
\hline \multicolumn{10}{|l|}{ pH 11} \\
\hline 200 & 0.0581 & 150.58 & 162.23 & 0.0618 & 153.27 & 164.26 & 0.0760 & 156.35 & 165.78 \\
\hline 500 & 0.1118 & 300.61 & 313.78 & 0.1133 & 378.16 & 393.77 & 0.1499 & 399.78 & 411.77 \\
\hline 800 & 0.1388 & 309.77 & 322.61 & 0.1116 & 443.49 & 459.39 & 0.1954 & 630.45 & 644.18 \\
\hline
\end{tabular}

Table 7

Kinetic parameters of pseudo-second order for MB dye adsorption onto JAC.

\begin{tabular}{|c|c|c|c|c|c|c|c|c|c|}
\hline \multirow[t]{2}{*}{$C_{0}, \mathrm{mg} / \mathrm{L}$} & \multicolumn{3}{|l|}{ JAC-1 } & \multicolumn{3}{|l|}{ JAC-2 } & \multicolumn{3}{|l|}{ JAC-3 } \\
\hline & $k_{2}(\mathrm{~g} / \mathrm{mg} \min )$ & $q_{e}(\mathrm{mg} / \mathrm{g})$ & $q_{e} \exp (\mathrm{mg} / \mathrm{g})$ & $k_{2}(\mathrm{~g} / \mathrm{mg} \min )$ & $q_{e}(\mathrm{mg} / \mathrm{g})$ & $q_{e} \exp (\mathrm{mg} / \mathrm{g})$ & $k_{2}(\mathrm{~g} / \mathrm{mg} \min )$ & $q_{e}(\mathrm{mg} / \mathrm{g})$ & $q_{e} \exp (\mathrm{mg} / \mathrm{g})$ \\
\hline \multicolumn{10}{|l|}{$\mathrm{pH} 3$} \\
\hline 200 & 0.0003 & 147.38 & 146.33 & 0.0006 & 163.79 & 163.21 & 0.0008 & 165.73 & 164.65 \\
\hline 500 & 0.0004 & 173.42 & 173.92 & 0.0006 & 308.50 & 307.29 & 0.0009 & 385.99 & 383.33 \\
\hline 800 & 0.0004 & 177.11 & 175.50 & 0.0005 & 314.38 & 313.68 & 0.0009 & 414.11 & 413.13 \\
\hline \multicolumn{10}{|l|}{$\mathrm{pH} 7$} \\
\hline 200 & 0.0007 & 160.85 & 160.85 & 0.0008 & 164.05 & 163.31 & 0.0009 & 165.98 & 165.61 \\
\hline 500 & 0.0008 & 282.31 & 281.28 & 0.0008 & 347.60 & 346.28 & 0.0009 & 410.38 & 411.06 \\
\hline 800 & 0.0009 & 288.03 & 288.93 & 0.0009 & 361.26 & 360.93 & 0.0010 & 597.93 & 598.80 \\
\hline \multicolumn{10}{|l|}{ pH 11} \\
\hline 200 & 0.0006 & 161.97 & 162.23 & 0.0006 & 163.94 & 164.26 & 0.0008 & 166.07 & 165.78 \\
\hline 500 & 0.0006 & 314.17 & 313.78 & 0.0007 & 392.98 & 393.77 & 0.0009 & 411.39 & 411.77 \\
\hline 800 & 0.0007 & 323.31 & 322.61 & 0.0008 & 459.39 & 459.39 & 0.0009 & 645.08 & 644.18 \\
\hline
\end{tabular}

where $R$ is the universal gas constant $(8.314 \mathrm{~J} / \mathrm{mol} \mathrm{K}), T$ is temperature $(\mathrm{K})$ and $K_{\mathrm{D}}$ is the thermodynamic distribution coefficient $\left(K_{\mathrm{D}}=q_{\mathrm{e}} / C_{\mathrm{e}}\right)$. The enthalpy and entropy change were correlated to the $K_{\mathrm{D}}$ by Van't Hoff equation which expressed as follow:

$\ln K_{\mathrm{D}}=-\frac{\Delta H^{0}}{R T}+\frac{\Delta S^{0}}{R}$

The value of $\Delta H^{0}$ and $\Delta S^{0}$ was obtained from the slope and the intercept from the linear plot of $\ln K_{\mathrm{D}}$ versus $1 / T$ (Fig. 6), respectively. The calculated thermodynamic parameters were summarized in Table 8 . From this table it can be seen that all systems showed the favorability of the process and spontaneous nature of dye adsorption onto JAC carbons.

By increasing the temperature, more negative value of $\Delta G^{0}$ was observed; this phenomenon indicates that higher temperatures are more preferred for higher sorption results. The binding affinity of adsorbate molecules toward adsorbent surface increased with the increased of temperature. The positive value of $\Delta H^{0}$ reveals that the adsorption process is endothermic in nature and could be classified into chemisorption since all of $\Delta H^{0}$ values fall into the range of $20.9-418.4 \mathrm{~kJ} / \mathrm{mol}$ (Tan et al., 2011). On the other hand, the positive value of $\Delta S^{0}$ denotes the increased in randomness at solid-solution interface during

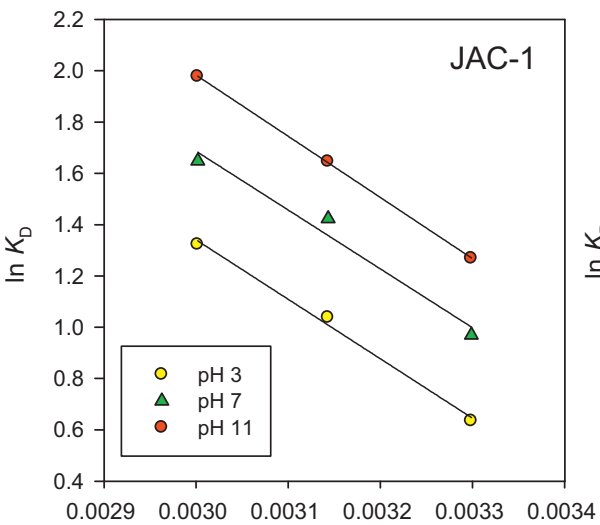

$1 / \mathrm{T}\left(\mathrm{K}^{-1}\right)$

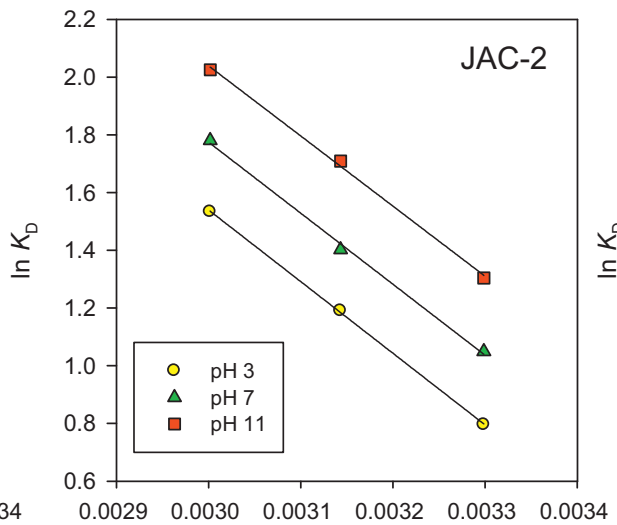

$1 / \mathrm{T}\left(\mathrm{K}^{-1}\right)$

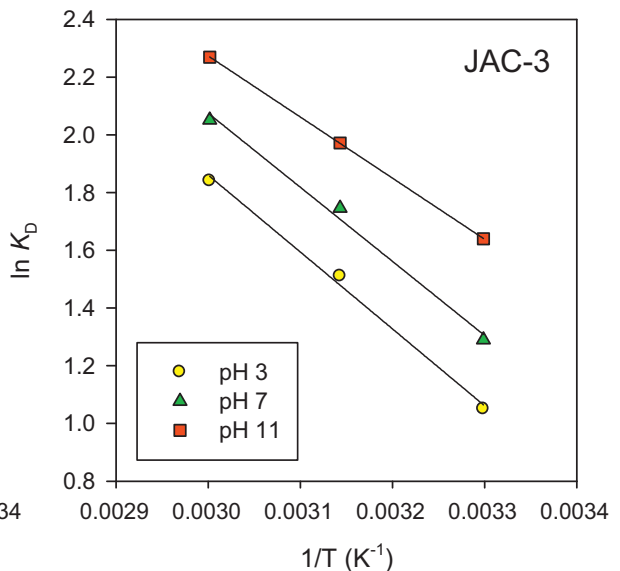

$1 / \mathrm{T}\left(\mathrm{K}^{-1}\right)$

Fig. 6. Thermodynamic plots of $\ln K_{\mathrm{D}}$ versus $1 / T$ for MB dye adsorption onto JAC. 

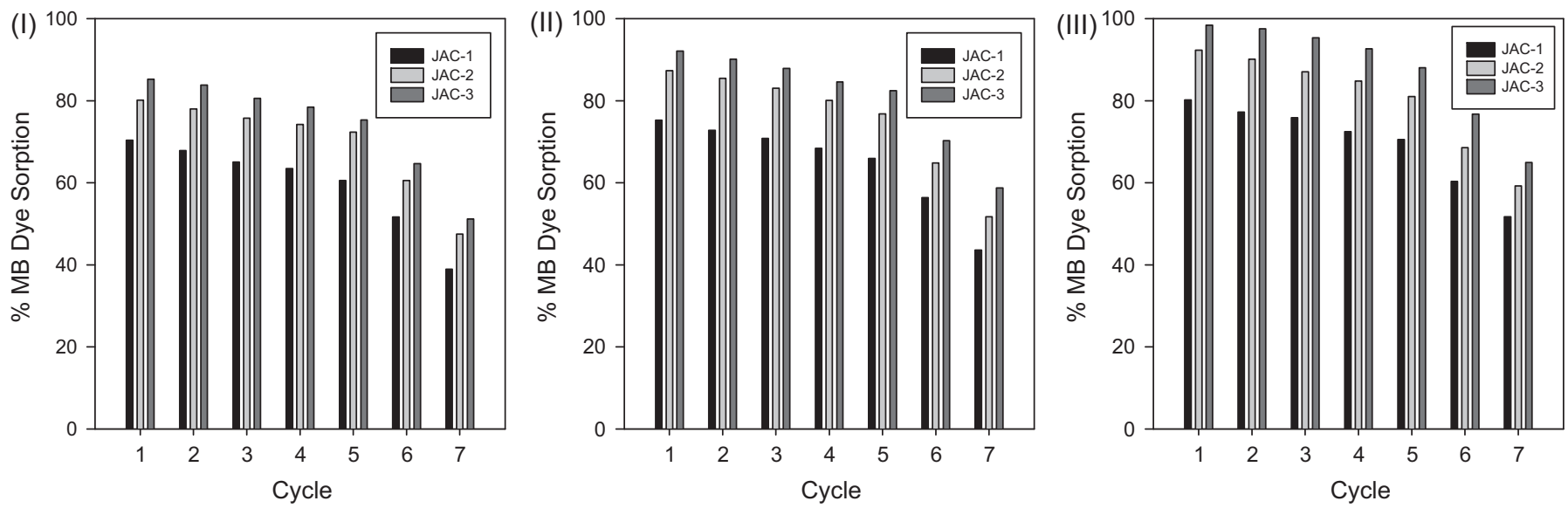

Fig. 7. Effect of recycling time on $\mathrm{MB}$ dye adsorption by JAC at pH 3 (I), pH 7 (II) and pH 11 (III).

Table 8

Thermodynamic parameters for MB dye adsorption onto JAC.

\begin{tabular}{|c|c|c|c|c|c|}
\hline $\mathrm{pH}$ & $T(\mathrm{~K})$ & $\Delta G^{0}(\mathrm{~kJ} / \mathrm{mol})$ & $\Delta H^{0}(\mathrm{~kJ} / \mathrm{mol})$ & $\Delta S^{0}(\mathrm{~kJ} / \mathrm{mol} \mathrm{K})$ & $R^{2}$ \\
\hline \multicolumn{6}{|l|}{ JAC-1 } \\
\hline \multirow[t]{3}{*}{3} & 303.15 & -1.5983 & 21.2082 & 0.0690 & 0.9948 \\
\hline & 318.15 & -2.7441 & & & \\
\hline & 333.15 & -3.6611 & & & \\
\hline \multirow[t]{3}{*}{7} & 303.15 & -2.4434 & 21.1790 & 0.0713 & 0.9727 \\
\hline & 318.15 & -3.5078 & & & \\
\hline & 333.15 & -4.5649 & & & \\
\hline \multirow[t]{3}{*}{11} & 303.15 & -3.1967 & 21.1567 & 0.0760 & 0.9999 \\
\hline & 318.15 & -4.5323 & & & \\
\hline & 333.15 & -5.4766 & & & \\
\hline \multicolumn{6}{|l|}{ JAC-2 } \\
\hline \multirow[t]{3}{*}{3} & 303.15 & -2.0043 & 21.6492 & 0.0747 & 0.9998 \\
\hline & 318.15 & -3.1469 & & & \\
\hline & 333.15 & -4.2453 & & & \\
\hline \multirow[t]{3}{*}{7} & 303.15 & -2.6429 & 21.4678 & 0.0762 & 0.9979 \\
\hline & 318.15 & -3.7104 & & & \\
\hline & 333.15 & -4.9325 & & & \\
\hline \multirow[t]{3}{*}{11} & 303.15 & -3.2879 & 21.2148 & 0.0776 & 0.9982 \\
\hline & 318.15 & -4.5208 & & & \\
\hline & 333.15 & -5.6114 & & & \\
\hline \multicolumn{6}{|l|}{ JAC-3 } \\
\hline \multirow[t]{3}{*}{3} & 303.15 & -2.6453 & 22.1634 & 0.0820 & 0.9954 \\
\hline & 318.15 & -3.9939 & & & \\
\hline & 333.15 & -5.0963 & & & \\
\hline \multirow[t]{3}{*}{7} & 303.15 & -3.2508 & 21.8355 & 0.0830 & 0.9925 \\
\hline & 318.15 & -4.6182 & & & \\
\hline & 333.15 & -5.6808 & & & \\
\hline \multirow[t]{3}{*}{11} & 303.15 & -4.1335 & 21.5060 & 0.0857 & 0.9998 \\
\hline & 318.15 & -5.2169 & & & \\
\hline & 333.15 & -6.2857 & & & \\
\hline
\end{tabular}

adsorption of dyes while the negative value of $\Delta S^{0}$ describes the opposite phenomena.

\subsection{Reusability of the adsorbent}

The reusability of the adsorbent is important in industrial practice. To assess the stability of the repeated used of JAC for MB dye removal, the adsorption-desorption cycles was also conducted. In this study, dilute hydrochloric acid was used as elution solution and the procedure was repeated seven times under following operating condition (initial dye concentration = $1000 \mathrm{mg} / \mathrm{L}$; contact time $=4 \mathrm{~h} ; T=30^{\circ} \mathrm{C}$; mass of adsorbent $=1 \mathrm{~g}$ ). The effect of recycling time on the adsorption capacity of JAC is given in Fig. 7. In this figure, it can be seen that all of JAC can be repeatedly used at least five times without significantly losing its adsorption capacity toward MB dye.

\section{Conclusions}

$J$. curcas $L$. press-cake residue can be utilized as new precursor for low cost activated carbon preparation. In order to improve the adsorption capacity for dyes removal, the surface properties of carbon could be tailored appropriately by chemical and thermal treatment. Based on the experimental results, it was found that thermal activated carbon (JAC-3) showed higher adsorption capacity for MB dye removal than the parent carbon (JAC-1) and oxidized carbon (JAC-2). The Langmuir model represented the experimental data better than Freundlich equation. The pseudosecond order model gave better representation in correlating kinetic data than pseudo-first order model. The adsorption of MB dye onto JAC was controlled by chemisorption mechanism. The thermodynamic behavior of the adsorption MB onto JAC carbons was endothermic $\left(\Delta H^{0}>0\right)$, irreversible $\left(\Delta S^{0}>0\right)$ and spontaneous $\left(\Delta G^{0}<0\right)$. Desorption studies indicated that all of JAC could be regenerated and reused at least five times without significantly losing its adsorption capacity.

\section{References}

Ai, L., H. Huang, Z. Chen, X. Wei, and J. Jiang, "Activated Carbon $/ \mathrm{CoFe}_{2} \mathrm{O}_{4}$ Composites: Facile Synthesis, Magnetic Performance and Their Potential Application for the Removal of Malachite Green from Water," Chem. Eng. J., 156, 243 (2010).

Altenor, S., B. Carene, E. Emmanuel, J. Lambert, J. J. Ehrhardt, and S. Gaspard, “Adsorption Studies of Methylene Blue and Phenol onto Vetiver Roots Activated Carbon Prepared by Chemical Activation," J. Hazard. Mater., 165, 1029 (2009).

Bhatnagar, A. and M. Sillanpaa, "Utilization of Agro-Industrial and Municipal Waste Materials as Potential Adsorbents for Water Treatment - A Review," Chem. Eng. J., 157, 277 (2010).

Boehm, H. P., "Surface Oxides on Carbon and Their Analysis: A Critical Assessment," Carbon, 40, 145 (2002).

Coughlin, R. W. and F. S. Ezra, "Role of Surface Acidity in the Adsorption of Organic Pollutants on the Surface of Carbon," Environ. Sci. Technol., 2, 291 (1968).

Demirbas, E., N. Dizge, M. T. Sulak, and M. Kobya, "Adsorption Kinetics and Equilibrium of Copper from Aqueous Solutions Using Hazelnut Shell Activated Carbon," Chem. Eng. J., 148, 480 (2009).

Draper, M. R. and J. H. Ridd, "Nitration of Mesitylene: Comparison with Reactions of the Cation-radical $\mathrm{C}_{6} \mathrm{H}_{3} \mathrm{Me}^{3+}, "$ J. Chem. Soc., Chem. Commun., 10, 445 (1978).

El Qada, E. N., S. J. Allen, and G. M. Walker, "Adsorption of Basic Dyes from Aqueous Solution onto Activated Carbons," Chem. Eng. J., 135, 174 (2008).

Faria, P.C. C., J.J.M. Orfao, and M. F. R. Pereira, "Adsorption of Anionic and Cationic Dyes on Activated Carbons with Different Surface Chemistries," Water Res., 38, 2043 (2004).

Fernandez, C., M. S. Larrechi, and M. P. Callao, "An Analytical Overview of Processes for Removing Organic Dyes from Wastewater Effluents," Trends Anal. Chem., 29, 1202 (2010).

Fierro, V., G. Muniz, A. H. Basta, H. El-Saied, and A. Celzard, "Rice Straw as Precursor of Activated Carbons: Activation with Ortho-phosphoric Acid," J. Hazard. Mater., 181, 27 (2010).

Foo, K. Y. and B. H. Hameed, "Utilization of Biodiesel Waste as a Renewable Resource for Activated Carbon: Application to Environmental Problems," Renew. Sustain. Energy Rev., 13, 2495 (2009)

Gad, H. M. H. and A. A. El-Sayed, "Activated Carbon from Agricultural By-products for the Removal of Rhodamine-B from Aqueous Solution," J. Hazard. Mater., 168, 1070 (2009). 
Ho, Y. S. and G. McKay, "Pseudo-second-order Model for Sorption Processes," Process Biochem., 34, 451 (1999).

Huang, G., J. X. Shi, and T. A. G. Langrish, "Removal of $\mathrm{Cr}(\mathrm{VI})$ from Aqueous Solution Using Activated Carbon Modified with Nitric Acid," Chem. Eng. J., 152, 434 (2009).

Jaramillo, J., P. M. Alvarez, and V. G. Serrano, "Oxidation of Activated Carbon by Dry and Wet Methods: Surface Chemistry and Textural Modifications," Fuel Process. Technol., 91, 1768 (2010).

Karagoz, S., T. Tay, S. Ucar, and M. Erdem, “Activated Carbons from Waste Biomass by Sulfuric Acid Activation and Their Use on Methylene Blue Adsorption," Bioresour. Technol., 99, 6214 (2008).

Khalid, Z., "Studies of the Photochemical Kinetics of Methylene Blue with Reductants," Ph.D. Thesis, Department of Chemistry, University of Karachi, Karachi, Pakistan (2001).

Kumar, P. S., S. Ramalingam, and K. Sathishkumar, "Removal of Methylene Blue Dye from Aqueous Solution by Activated Carbon Prepared from Cashew Nut Shell as a New Low-cost Adsorbent," Korean J. Chem. Eng., 28, 149 (2011).

Lagergren, S., "About the Theory of So-called Adsorption of Soluble Substances," Kungliga Svenska Vetenskapsakademiens. Handlingar, Band, 24, 1 (1898).

Leon y leon, C. A., J. M. Solar, V. Calemma, and L. R. Radovic, "Evidence for the Protonation of Basal Plane Sites on Carbon," Carbon, 30, 797 (1992).

Liu, Q. S., T. Zheng, N. Li, P. Wang, and G. Abulikemu, "Modification of Bamboo-based Activated Carbon Using Microwave Radiation and Its Effects on the Adsorption of Methylene Blue," Appl. Surf. Sci., 256, 3309 (2011).
Montes-Moran, M. A., D. Suarez, J. A. Menendez, and E. Fuente, "On the Nature of Basic Sites on Carbon Surfaces: An Overview," Carbon, 42, 1219 (2004).

Nethaji, S., A. Sivasamy, G. Thennarasu, and S. Saravanan, "Adsorption of Malachite Green Dye onto Activated Carbon Derived from Borassus aethiopum Flower Biomass," J. Hazard. Mater., 181, 271 (2010).

Nunes, A. A., A. S. Franca, and L. S. Oliveira, "Activated Carbons from Waste Biomass: An Alternative Use for Biodiesel Production Solid Residues," Bioresour. Technol., 100, 1786 (2009).

Raposo, F., M. A. De La Rubia, and R. Borja, “Methylene Blue Number as Useful Indicator to Evaluate the Adsorptive Capacity of Granular Activated Carbon in Batch Mode: Influence of Adsorbate/Adsorbent Mass Ratio and Particle Size," J. Hazard. Mater. 165, 291 (2009).

Stavropoulos, G. G. and A. A. Zabaniotou, "Production and Characterization of Activated Carbons from Olive-seed Waste Residue," Micropor. Mesopor. Mater., 82, 79 (2005).

Tan, C. Y., M. Li, Y. M. Lin, X. Q. Lu, and Z. L. Chen, "Biosorption of Basic Orange from Aqueous Solution onto Dried A. filiculoides Biomass: Equilibrium, Kinetic and FTIR Studies," Desalination, 266, 56 (2011).

Timur, S., I. C. Kantarli, S. Onenc, and J. Yanik, "Characterization and Application of Activated Carbon Produced from Oak Cups Pulp," J. Anal. Appl. Pyrol., 89, 129 (2010).

Wu, F. C., P. H. Wu, R. L. Tseng, and R. S. Juang, "Preparation of Novel Activated Carbons from $\mathrm{H}_{2} \mathrm{SO}_{4}$-pretreated Corncob Hulls with $\mathrm{KOH}$ Activation for Quick Adsorption of Dye and 4-Chlorophenol," J. Environ. Manage., 92, 708 (2011). 